\title{
Allometry and morphometry of blue whales photographed in the Gulf of California: insights into subspecies taxonomy in the Eastern North Pacific
}

\author{
Christian D. Ortega-Ortiz ${ }^{1,2}$, Víctor M. Gómez-Muñoz ${ }^{1}$, Diane Gendron ${ }^{1, *}$ \\ ${ }^{1}$ Instituto Politécnico Nacional, Centro Interdisciplinario de Ciencias Marinas, Ave IPN s/n, Col. Palo Playa de Santa Rita, \\ La Paz, Baja California Sur, CP 23096, México \\ ${ }^{2}$ Present address: Facultad de Ciencias Marinas, Universidad de Colima. Km 20 Carretera Manzanillo-Cihuatlán, \\ Manzanillo, Colima, CP 28860, México
}

\begin{abstract}
The Eastern North Pacific (ENP) blue whale population is considered the most recovered worldwide. Despite this, its subspecies taxonomy is yet to be resolved. A previous morphological analysis using vertical aerial photogrammetry on blue whales from the ENP suggested that they are morphologically similar to the Indian Ocean pygmy blue whale Balaenoptera musculus brevicauda. This subspecies has been discriminated from the Antarctic blue whale B. musculus intermedia by a shorter total length and a proportionally shorter caudal peduncle (from dorsal fin to notch of flukes), a difficult morphological characteristic to measure at sea. In this study, we present allometric and morphometric analyses of the caudal peduncle proportion in relation to total length based on photogrammetric data from whales observed in the Gulf of California, Mexico (a winter ground for the ENP population), to compare with caudal peduncle measurements available from both Southern Hemisphere subspecies. Throughout allometric analysis, the caudal peduncle showed negative growth as the individual got older, indicating that this body part differs according to age-class. Our morphometric analysis indicated that the caudal peduncle proportion of these blue whales was significantly larger than that of the Indian Ocean pygmy blue whale. The integration of our results with the previous photogrammetry study suggests that more than one morphotype inhabits the ENP, and highlights gaps in our knowledge on the taxonomy of these whales. The inexpensive photogrammetric technique used in this study could be easily combined with other studies to better understand and protect these endangered whale populations.
\end{abstract}

KEY WORDS: Balaenoptera musculus - Morphometry · Allometry · Caudal peduncle · Aerial photogrammetry $\cdot$ Subspecies

\section{INTRODUCTION}

The blue whale Balaenoptera musculus is currently listed as Endangered A1abd ver 3.1 (www. iucn.org/details/2477/0, downloaded 5 Sep 2018) due to population reductions on a global scale as a result of commercial whaling that are reversible because commercial whaling no longer takes place (Reilly et al. 2008). In the past, a single subspecies

*Corresponding author: dianegendroncicimar@gmail.com name, B. m. musculus, was applied to all blue whales inhabiting the Northern Hemisphere, both in the Atlantic and Pacific Oceans (Rice 1998). This subspecies was distinguished from the Antarctic blue whale, B. m. intermedia, which is relatively larger and shows a putative geographical segregation into the Southern Hemisphere (Mackintosh \& Wheeler 1929). However, there are no other morphological measurements for B. m. musculus from

() The authors 2018. Open Access under Creative Commons by Attribution Licence. Use, distribution and reproduction are unrestricted. Authors and original publication must be credited. 
whaling operations, e.g. caudal peduncle proportion in relation to total length, which could be used in a comparative study between these subspecies.

The pygmy blue whale $B . m$. brevicauda is differentiated from the Antarctic blue whale by morphological features, such as its shorter total length, shorter baleen plates (in relation to their width), sexual and physical maturity at a shorter total length, and mainly by a proportionally shorter caudal peduncle (Ichihara 1961, 1966). Kato et al. (1995) used this morphological feature to identify pygmy blue whales in historical catch records and showed that the pygmy and Antarctic subspecies were geographically segregated during the austral summer, with the pygmy subspecies being exclusively distributed in the waters to the north of the Sub-Antarctic Convergence, and into the Indian Ocean. However, the proportional length of the caudal peduncle is a difficult morphological characteristic to measure from freeliving blue whales. LeDuc et al. (2007) concurred, and questioned subspecies identity based on morphological distinction criterion observed at sea. They therefore used feeding ground segregations as a proxy for subspecies identity in a molecular analysis carried out on free-ranging blue whales biopsied in the Southern Ocean.

Nonetheless, several studies using catch, sighting, morphology, behavior and acoustic data have suggested a broader distribution for the pygmy subspecies within the Southern Hemisphere (Alling et al. 1991, Kato et al. 1995, Ljungblad et al. 1998, McDonald et al. 2006, Branch et al. 2007, Branch \& Mikhalev 2008). Furthermore, based on a morphometric analysis using total length and caudal peduncle proportion measured through vertical aerial photogrammetry (VAP), Gilpatrick \& Perryman (2008) concluded that blue whales from the eastern North Pacific (ENP) population are morphologically similar to the pygmy type described from the Indian Ocean, and differ from the other recognized subspecies.

Based on whaling data and survey sightings made in the 1960s along the North American coast, Rice (1974) proposed that the blue whales distributed along the coastal area, from Alaska and the eastern Aleutian Islands to beyond the Baja California Peninsula, formed a distinct ENP population separate from the rest of the North Pacific. Subsequent information obtained from photo-identification, satellite tracking and acoustic recordings supports Rice's (1974) concept of a separate ENP population following seasonal north-south movements along the coast of Central and North America (Calambokidis et al. 1990, 2009, Mate et al. 1999, Stafford et al. 2001, Bailey et al.
2009), between their summer feeding grounds off the western coast of North America (Schoenherr 1991, Fiedler et al. 1998, Larkman \& Veit 1998, Croll et al. 2005), their winter nursing areas in the Gulf of California (Gendron 2002, Sears et al. 2013) and the Costa Rica Dome (Mate et al. 1999, Bailey et al. 2009). This population is considered to be the most fully recovered of blue whale populations (Sears \& Calambokidis 2002), and a recent analysis of its population dynamics also suggested that it has reached stability (Monnahan et al. 2015).

Blue whales visiting the Gulf of California, a winter area for this ENP population, have been monitored for more than $25 \mathrm{yr}$, and a comprehensive sighting history database of over 650 identified individuals has been assembled (Gendron \& Ugalde de la Cruz 2012). Recently, molecular research through microsatellite analyses showed that the Gulf of California is used by individuals from a single population unit (Costa-Urrutia et al. 2013), whose members display long seasonal residency (i.e. 2 to 3 mo) and annual return (Gendron 2002). Analyses of the detection frequency of blue whale vocalizations also suggests an extended seasonal presence with a clear movement from the southern to the northern region during November, and subsequent southern movement in March (Paniagua-Mendoza et al. 2017). Finally, high progesterone and corticosterone metabolites found in the feces of several female blue whales compared with metabolites from lactating and resting females confirm that the Gulf of California is an important winter-spring area for the reproductive phase of these blue whales (Valenzuela-Molina et al. 2018).

Despite this, however, scientific information about the taxonomy of the ENP blue whale subspecies is scarce. This was noted by LeDuc et al. (2017, p. 750), who noted, 'The morphological similarities between blue whales from the ENP and the pygmy blue whale from the Indian Ocean reported by Gilpatrick \& Perryman (2008) were not congruent with the genetic differences, leaving its taxonomic status unresolved'. In the IUCN report on blue whales, the question of whether the ENP is composed of more than one subspecies has been raised, and it has been suggested that comparable evidence on body measurements (from catches or photogrammetry) is necessary to address this gap in our knowledge (Reilly et al. 2008). Thus, in this study, we used allometric and morphometric analyses of the caudal peduncle obtained from VAP of adult blue whales in the Gulf of California to compare this morphological feature with data from the Southern Hemisphere subspecies. 


\section{MATERIALS AND METHODS}

\section{Data sources}

Photogrammetric data

Aerial photographs were taken whenever possible during a research project to estimate the number of blue whales using the Gulf of California during winter and spring from 2001 to 2007 (Fig. 1). Aerial photography was carried out from a Cessna 182 aircraft, at an altitude of 200 to $300 \mathrm{~m}$. In the course of 26 survey flights (approximately $4 \mathrm{~h}$ each), a total flight path of $4611 \mathrm{~km}$ was covered systematically to avoid registering duplicate sightings and photographs of the same individual during the same flight. The images were obtained using several cameras: an analog Canon EOS A2 (prints were digitized in high resolution to avoid high grain and to be able to locate and measure the dorsal fin with accuracy and precision), a digital Canon EOS 10D and a digital Nikon D200. All cameras were equipped with a 70 to $300 \mathrm{~mm}$ telephoto lens. To achieve vertical shots of each whale, the photographs were taken from an open window with the aircraft tilted toward the photographer's side.

Images were included in the analyses only if they complied with 4 selection criteria: (1) orientation perpendicular to the whale, (2) sharp definition, (3) they showed the whale body straight and aligned parallel to the sea surface, and (4) the total length and the cau- dal peduncle were easily measurable. When more than one image was available for a particular individual photographed in sequential shots, the best one was selected. Because imprecise altitude readings at the moment of taking the aerial photographs made it difficult to convert peduncle measurement into meter units, the caudal peduncle measurement using the number of pixels was standardized by dividing it by the whale's total body length, also measured in number of pixels appreciable in the image. All digital images were analyzed using Sigma Scan Pro v.4 software. Therefore, it is important to keep in mind that the morphometric comparison is presented in terms of proportion of the total length.

\section{Sources of variability in the photogrammetric data}

In order to evaluate the sources of variability $(E)$ involved in our VAP technique (which was also used by Angliss et al. 1995), we conducted independent experiments to determine the coefficient of variation (CV) of $\left(E_{1}\right)$ technical error associated with equipment and scale, which was determined by measuring the size of a locker known to be exactly $0.9 \mathrm{~m}$ in length, located in the stern of our research boat (considering a similar method of calculation to that used for the measurement of the caudal peduncle proportion); $\left(E_{2}\right)$ biological variability associated with the target ani-

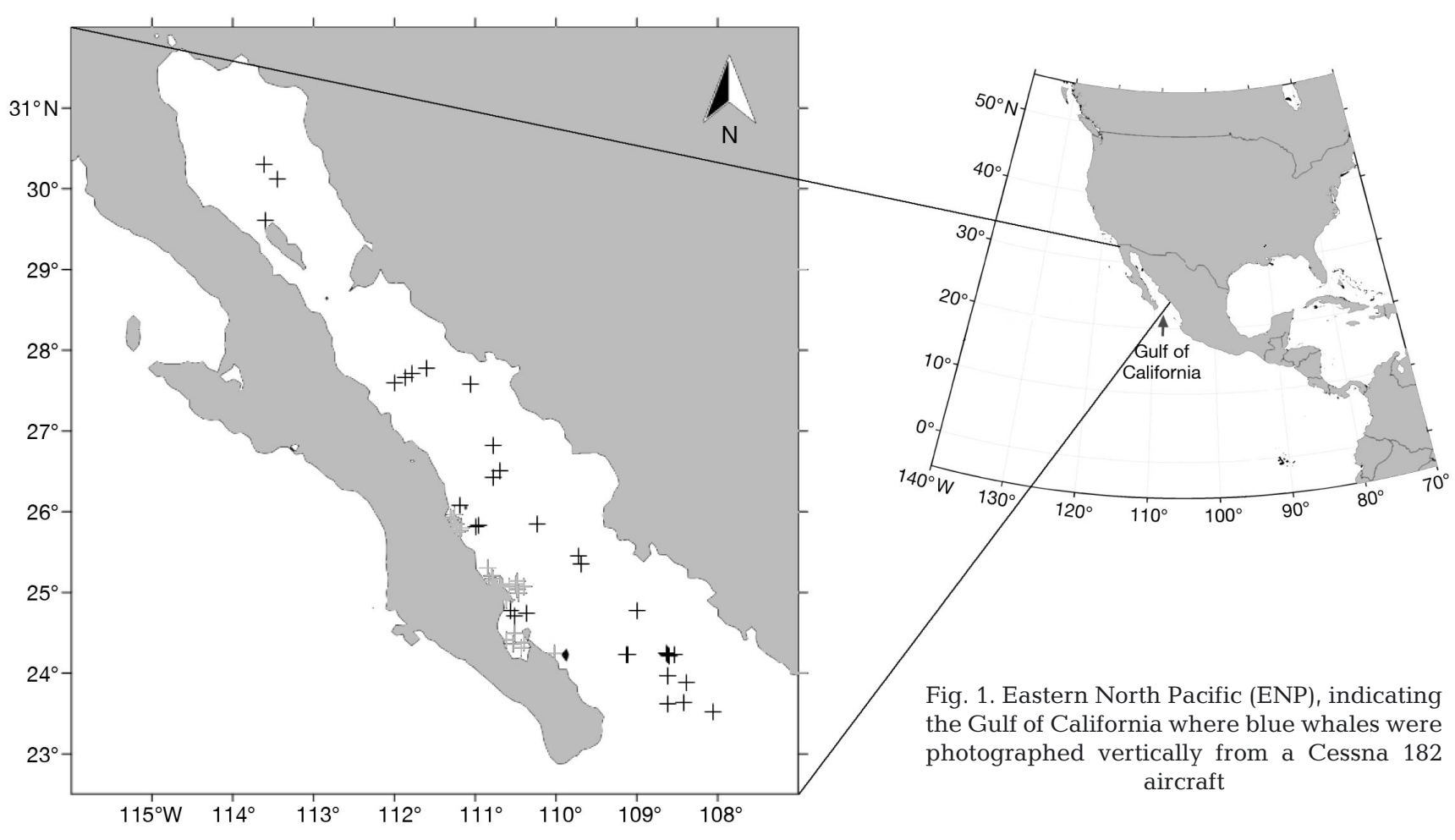


mal - this was evaluated by comparing the results of the caudal peduncle proportion for 7 different blue whale individuals using 3 aerial images taken in sequential frames for each whale; and $\left(E_{3}\right)$ observer variability associated with skill in measuring photographs. This was evaluated using measurements produced by 3 observers, each of whom measured the caudal peduncle proportion from the same set of 16 aerial images of different blue whale individuals. See Table 1 and the Appendix for details of experiment equations for these 3 sources of variability.

\section{Whaling data}

Measurements of total length and caudal peduncle proportion for Balaenoptera musculus intermedia from South Georgia ( $\mathrm{n}=353)$, South Africa $(\mathrm{n}=202$ ) (Mackintosh \& Wheeler 1929), and B. m. brevicauda $(\mathrm{n}=57)$ taken in the Sub-Antarctic (Omura 1984) were used in the allometric and morphometric analyses described below.

\section{Allometric analysis}

Mackintosh \& Wheeler (1929) showed that the caudal peduncle length changed in relation to changes in head size and suggested that these morphological changes were related to ontogenic development. However, to date, a formal analysis of blue whale growth pattern has not been conducted. In order to verify if the growth pattern of the caudal peduncle is related to length data for the 2 southern subspecies, we compared measurements provided from whaling with data from 4 individual blue whales from the Gulf of California, whose total length could be determined by vertically photographing the whales alongside an object of known size (research boat 'CICIMAR XV'; $9.8 \mathrm{~m}$ ) on several occasions, which functioned as measurement reference to estimate total lengths in meter units (Fig. 2).

Following Katsanevakis et al. (2007), we used the allometric equation of Huxley $(1924,1932)$, expressed in $\log _{10}$ units (Eq. 1) to calculate the linear relationship between the total length (from tip of the snout to notch of the flukes), taken as reference dimension (Katsanevakis et al. 2007), and the proportional length of the caudal peduncle (from the tip of the dorsal fin to the notch of the flukes) measured for each whale:

$$
\log Y=b(\log X)+\log a
$$

where $X=$ total length of the body (in m), $Y=$ proportional length of the caudal peduncle, $\log a=$ the

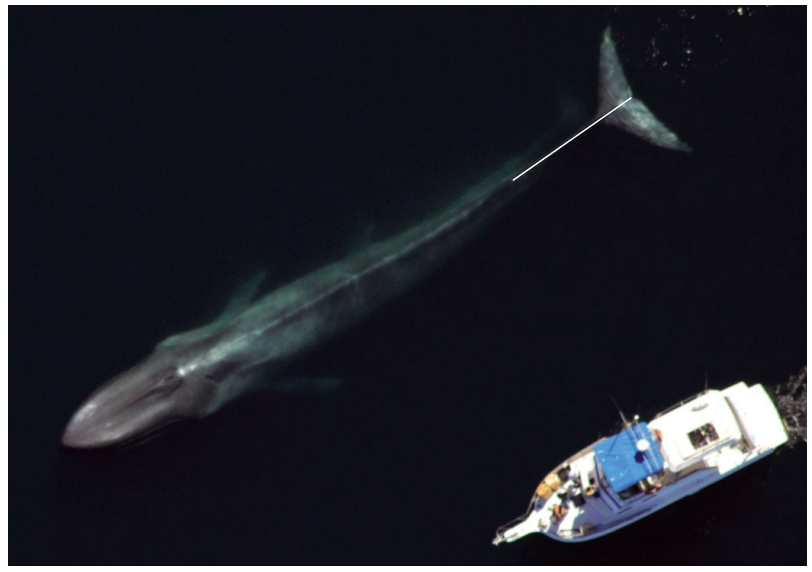

Fig. 2. Aerial photograph taken in the Gulf of California of a blue whale alongside a research boat of known length $(9.8 \mathrm{~m})$. White line on the whale: caudal peduncle length from the upper part of the dorsal fin (observed as a small black protuberance) to the notch of the flukes

$y$-axis intercept, and $b=$ the slope, or allometric coefficient, which is the relative growth between $X$ and $Y$ over time. Isometric growth occurs when $b=1$; a positive allometry is indicated when $b>1$, and when $b<$ 1 relative growth is negative (Schmidt-Nielsen 1984).

Furthermore, to corroborate a relationship between peduncle growth and age class (non-adults and adults) of the individuals, we measured the caudal peduncle proportion of 6 adult female/calf pairs photographed together that were distinguished by a considerable difference in their total sizes in several vertical photographs taken during the aerial surveys conducted in 2007. This provided both a proportional measurement between the females (adults) and calves (non-adults). A peduncle proportional size comparison between adults and calves in such photographs was done using the Wilcoxon matched pairs test (Zar 1996).

\section{Morphometric analysis}

The caudal peduncle proportions for B. m. intermedia and $B$. $m$. brevicauda were taken from whaling data, while the proportions for whales distributed in the Gulf of California were obtained through VAP. Both resources are described above.

\section{Peduncle proportion comparison for adult blue whales}

The identity of the blue whales photographed in our study was unknown, i.e. the total size and sex- 
ual maturity or any other biological parameter that suggested individual age class. In order to render our photogrammetric data set comparable to the morphology of adults from 2 southern subspecies measured during the whaling period, we calculated the caudal peduncle proportion of all adult individuals of B. $m$ intermedia (Mackintosh \& Wheeler 1929) and B. m. brevicauda (Omura 1984) data to obtain a caudal peduncle proportion as age class reference. Studies have shown that males and females of $B . m$. intermedia have reached sexual maturity, and are therefore considered adults, when they attain a mean total length of $22 \mathrm{~m}$ (Mackintosh \& Wheeler 1929, Gambell 1979); individuals of B. $m$. brevicauda are considered sexual mature when they attain a total length of $20 \mathrm{~m}$ (Ichihara 1966), while the estimated length at sexually maturity for B. m. musculus caught in the waters off California was $20.4 \mathrm{~m}$ (Rice 1963). From Mackintosh \& Wheeler's (1929) dataset, we calculated that the peduncle was less than $25 \%$ of the total length for all adults of $B$. m. intermedia ( $>22 \mathrm{~m}_{i} \mathrm{n}=223$ ). From Omura's (1984) data set, we calculated that all adults $\left(>20 \mathrm{~m}_{i} \mathrm{n}=49\right)$ of $B . \mathrm{m}$. brevicauda showed a peduncle size less than $25.3 \%$ of their total length. Similar values for the peduncle proportion $(<25 \%)$ were calculated from 2 adults $(>20.4 \mathrm{~m})$ measured alongside the boat (see Table 1) and from the 6 adult female/calf pairs.

For this morphology comparison, we discarded from our analysis 7 non-adult $B$. m. brevicauda, 332 nonadult B. m. intermedia and 23 individuals photographed in the Gulf of California because their caudal peduncle proportion was greater than $25 \%$ of the total length. The peduncle proportion data for adult individuals were analyzed for normality, and then the different data sets were compared using non-parametric statistics, Kolmogorov-Smirnov for distribution comparison (Steel \& Torrie 1988), Kruskal-Wallis for difference among groups, and Scheffé to test for significant difference between means, all results being considered significant at $\mathrm{p}<0.05$ (Zar 1996).

\section{RESULTS}

\section{Aerial photographs of blue whales from the Gulf of California}

A total of 351 aerial images of blue whales were taken, of which 82 images complied with the first 3 selection criteria. These were obtained in all regions of the Gulf of California: $75 \%$ from the southwestern region, $15.8 \%$ from the entrance and $8.5 \%$ from the northern region (Fig. 1). However, only 58 of these images also complied with the $4^{\text {th }}$ selection criteria (caudal peduncle and total length easily measured). In addition, 7 images corresponding to 4 different blue whale individuals had an object of known size (research boat) photographed alongside, allowing the whale's absolute size to be measured. In addition, 6 female/calf pairs were photographed during different years of the study period. Table 1 lists our evaluation of 3 potential sources of variability of the caudal peduncle measurement by simulating it with a known object (technical error) or by measuring it on blue whales (biological and observer variability). The mean proportion provided for the technical error was the largest at $0.98 \%(\mathrm{CV}=6.27 \%)$, the biological at $0.64 \%(\mathrm{CV}=3.74 \%)$ and observer at $0.3 \%(\mathrm{CV}=1.59 \%)$.

\section{Allometric relationship}

The relationship between the proportional length of the caudal peduncle and total length showed negative allometric growth in both southern subspecies and in 4 blue whales from the Gulf of California (Table 2), indicating that the peduncle exhibited slow growth with respect to the total length increase (Fig. 3). The allometric coefficient for Balaenoptera musculus brevicauda was the smallest $(b=-0.041)$ and showed the weakest and nonsignificant $(\mathrm{p}>$ $0.05)$ determination coefficient $\left(\mathrm{R}^{2}=0.0011\right.$; Fig. 3$)$.

\section{Relation between age classes and allometric growth}

The allometric growth of the peduncle indicates that small-sized blue whales, i.e. calves and juveniles, possess a relatively larger peduncle than adults. The total length and the caudal peduncle proportion measured on 4 individuals from the Gulf of California, on 7 vertical aerial photographs in which both whale and research boat were visible, showed that 1 calf and 1 juvenile had larger peduncles (27.06 and $25.18 \%$, respectively) than the other 2 adults (24.2 and $23.31 \%$ ) (Table 2). In the same context, from the 6 vertical aerial photographs of female/calf pairs we showed a mean peduncle proportion of $23.5 \%$ (range: 23.09 to $23.91 \%$ ) for adult females, and $26.85 \%$ (range: 25.18 to $28.3 \%$ ) for the calves. The difference between these age classes was significant $\left(Z_{5,0}=2.02, \mathrm{p}<0.05\right)$. 
Table 1. Sources of variability of the peduncle proportion in relation to the total length using the aerial photogrammetric technique employed in the Gulf of California: technical error, $E_{1}$; biological error, $E_{2}$; and observer variability, $E_{3}$. See 'Materials and methods' for explanations and Appendix for equations. n: number of images measured $\mathrm{CV}$ : mean of the coefficient of variation (-: measurements made on a single object, so no CV calculable)

\begin{tabular}{|lccccc|}
\hline Source & $\begin{array}{c}\text { Estimate } \\
(\%)\end{array}$ & $\begin{array}{c}\text { Source } \\
\text { interval (\%) }\end{array}$ & $\begin{array}{c}\text { CV } \\
(\%)\end{array}$ & $\begin{array}{c}\text { CV interval } \\
(\%)\end{array}$ & $\mathrm{n}$ \\
\hline$E_{1}$ & 0.98 & $0.17-1.66$ & 6.27 & - & 18 \\
$E_{2}$ & 0.64 & $0.12-0.94$ & 3.74 & $0.66-5.52$ & 21 \\
$E_{3}$ & 0.30 & $0.02-0.73$ & 1.59 & $0.1-3.94$ & 16 \\
\hline
\end{tabular}

\section{Morphometric comparisons}

By comparing the statistical distribution of the peduncle proportion of all individual whales (Fig. 4), a similar distribution was observed among $B . \mathrm{m}$. intermedia from South Africa $(\mathrm{n}=202)$, B. m. intermedia from South Georgia $(\mathrm{n}=353)$ and whales photographed in the Gulf of California $(n=58)$. The distribution of the peduncle proportion for B. m. brevicauda ( $\mathrm{n}=57$ ) showed significant differences to each of the other 3 distribution sets respectively (Kolmogorov-Smirnov $D=0.86,0.81$ and 0.72, $\mathrm{p}<0.05$ ).

For the adult data set, the distribution of the peduncle proportion of $B$. m. brevicauda (19.7 to $23.98 \%, \mathrm{n}=50$ ), B. m. intermedia (South Africa: 23.0 to $25.18 \%, \mathrm{n}=51$; South Georgia: 23.05 to $24.84 \%, \mathrm{n}=235)$, and those photographed in the Gulf of California (23.03 to $24.85 \%, \mathrm{n}=35$ ) showed significant difference $(D=0.82,0.81$ and 0.67 , respectively) and with different modal class (see black arrows in Fig. 4). The peduncles of adult whales from South Georgia and Gulf of California showed a similar size-frequency distribution with a coincident modal class (between 23.5 and 24.5\%), while $B . m$. brevicauda showed a clearly distinct size-frequency distribution (probable mode between 21.5 and $22.5 \%$; Fig. 4).
The mean of the peduncle size for adult blue whales showed significant differences (Kruskal-Wallis, $\left.H_{3,371}=121.68, \mathrm{p}<0.05\right)$. Particularly the mean for blue whales photographed in the Gulf of California $(23.75 \%)$ was not significantly different from those from South Georgia (23.98\%), but it was significantly different (Scheffé test, $\mathrm{p}<0.05$ ) from those from South Africa $(24.35 \%)$ and B. m. brevicauda $(22.2 \%)$.

\section{DISCUSSION}

Our results were based on a geographically welldefined portion of the ENP blue whale population that winters in the Gulf of California, a known calving/ nursing area (Gendron 2002, Sears et al. 2013). We used an aerial photograph data set that had been collected over several years in the Gulf of California, employing a rigorous selection criteria on these photographs. The evaluation of the variability in the calculations showed a small difference $(<1 \%)$ for the mean of caudal peduncle proportion simulated with a known object or measured on blue whale individuals (see Table 1). The largest part of the variability was related to technical error $(\mathrm{CV}=6.2 \%)$, probably due to the focus on the whale rather than the boat, which was not totally perpendicular to the camera, and also due to the difficulty in distinguishing the edges of the white locker used as the scale. Despite this, the biological and observer variability were small $(\mathrm{CV}=3.7$ and $1.6 \%$, respectively). In photogrammetric studies, both high and low variabilities have been reported, e.g. Cubbage \& Calambokidis (1987) with a CV of 0.57\%, Angliss et al. (1995) with a CV <1\%, Perryman \& Lynn (1993) with a CV of $0.018 \%$ for cetacean total length estimation; compared to Ratnaswamy \& Winn (1993) reporting a CV of $10 \%$ and Cosens \& Blouw (2003) a CV of 4 to $9 \%$ also for cetacean total length estimation. However, the variability of the caudal peduncle estimation has only been reported by Gilpatrick \& Perryman (2008), with a CV of $4 \%$ (range: 0.66 to $7.31 \%$ ), similar to that obtained in our research. These results

Table 2. Total length and peduncle proportion (\%, in relation to the total length) for 4 Gulf of California blue whales of different age class measured from aerial photographs including the research boat of known length

\begin{tabular}{|c|c|c|c|c|c|c|}
\hline \multirow{2}{*}{$\begin{array}{l}\text { Blue } \\
\text { whale }\end{array}$} & \multirow{2}{*}{$\begin{array}{c}\text { No. of } \\
\text { images }\end{array}$} & \multicolumn{2}{|c|}{ — Total length $(\mathrm{m})$} & \multicolumn{2}{|c|}{- Peduncle $(\%)$} & \multirow{2}{*}{$\begin{array}{l}\text { Inferred } \\
\text { age class }\end{array}$} \\
\hline & & Mean & Range & Mean & Range & \\
\hline 1 & 2 & 13.49 & $13.41-13.57$ & 27.06 & $27.06-27.07$ & Calf \\
\hline 2 & 1 & 18.39 & - & 25.88 & - & Juvenile \\
\hline 3 & 2 & 22.71 & $22.47-22.96$ & 24.2 & $23.87-24.53$ & Adult \\
\hline 4 & 2 & 23.16 & $23.01-23.31$ & 23.31 & $23.06-23.57$ & Mature female (with a calf) \\
\hline
\end{tabular}




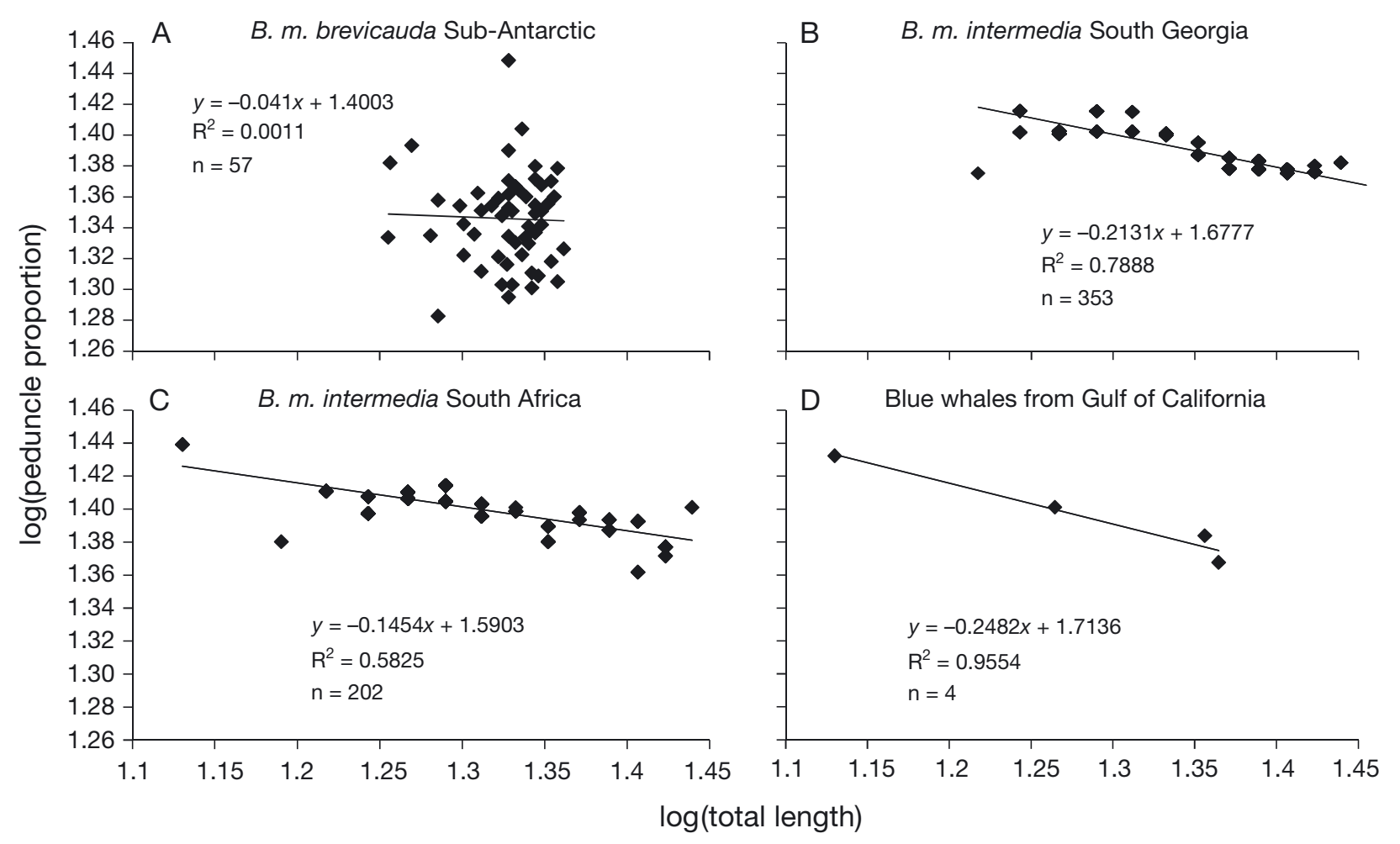

Fig. 3. Allometric relationship between the peduncle proportion and the total length (in $\mathrm{m}$ ) for the subspecies (A) Balaenoptera musculus brevicauda from the Sub-Antarctic (data from Omura 1984); B. m. intermedia from (B) South Georgia and (C) South Africa (data from Mackintosh \& Wheeler 1929); and (D) whales photographed in the Gulf of California (this study, details in Table 2). Allometric coefficient ( $b$, first value of the equation), determination coefficient $\left(\mathrm{R}^{2}\right)$ and sample size (n) are included inside each graph

demonstrate the reliability of our data by providing valid measurements of the caudal peduncle as a proportion of the whale's total length that can be compared to measurements obtained from other morphometric studies (e.g. Gilpatrick \& Perryman 2008, Durban et al. 2016), if the data are available.

\section{Allometric growth}

Allometry describes the relationship of body parts to the total length of the individual (Katsanevakis et al. 2007). Other studies on baleen whales using this technique have shown that larger fin whales Balaenoptera physalus and bowhead whales Balaena mysticetus have larger skulls and buccal cavities relative to their body size, and that this positive allometry is accompanied by negative allometry in the caudal peduncle (Goldbogen et al. 2010, Armfield et al. 2011).

In agreement with these studies, the caudal peduncle of the whales analyzed in this study displayed a negative allometric relationship, growing at a slower rate in comparison to the total length increase. This was determined by analyzing the information in pro- portion units (Fig. 3) albeit based on a small sample size $(n=4)$. Supporting this, our analysis of images of distinct size classes confirmed that the proportional caudal length is smaller in older animals. Interestingly, the proportional length of the caudal peduncle $(25.88 \%)$ of an individual with a total length measuring $18.39 \mathrm{~m}$ (Table 2) coincides with the peduncle proportion $(25.0 \%)$ of an $18.0 \mathrm{~m}$ immature male stranded in the Gulf of California reported by Valdez-Márquez et al. (2004).

A disproportionate growth between head size and the caudal peduncle in Balaenoptera musculus intermedia was identified earlier by Mackintosh \& Wheeler (1929), but no formal allometric analysis was performed. Our study confirmed that this growth pattern occurs in both southern subspecies and whales in the Gulf of California. Remarkably, the data for B. m. brevicauda showed an allometric coefficient closer to zero (-0.041), which suggests a poor relationship between compared variables, e.g. whales with a total length of $21.5 \mathrm{~m}$ that were registered with a caudal peduncle proportion ranging from 20 to $24.5 \%$, and 1 individual that showed the largest peduncle size at $28 \%$ of its total length (Omura 1984). One explana- 


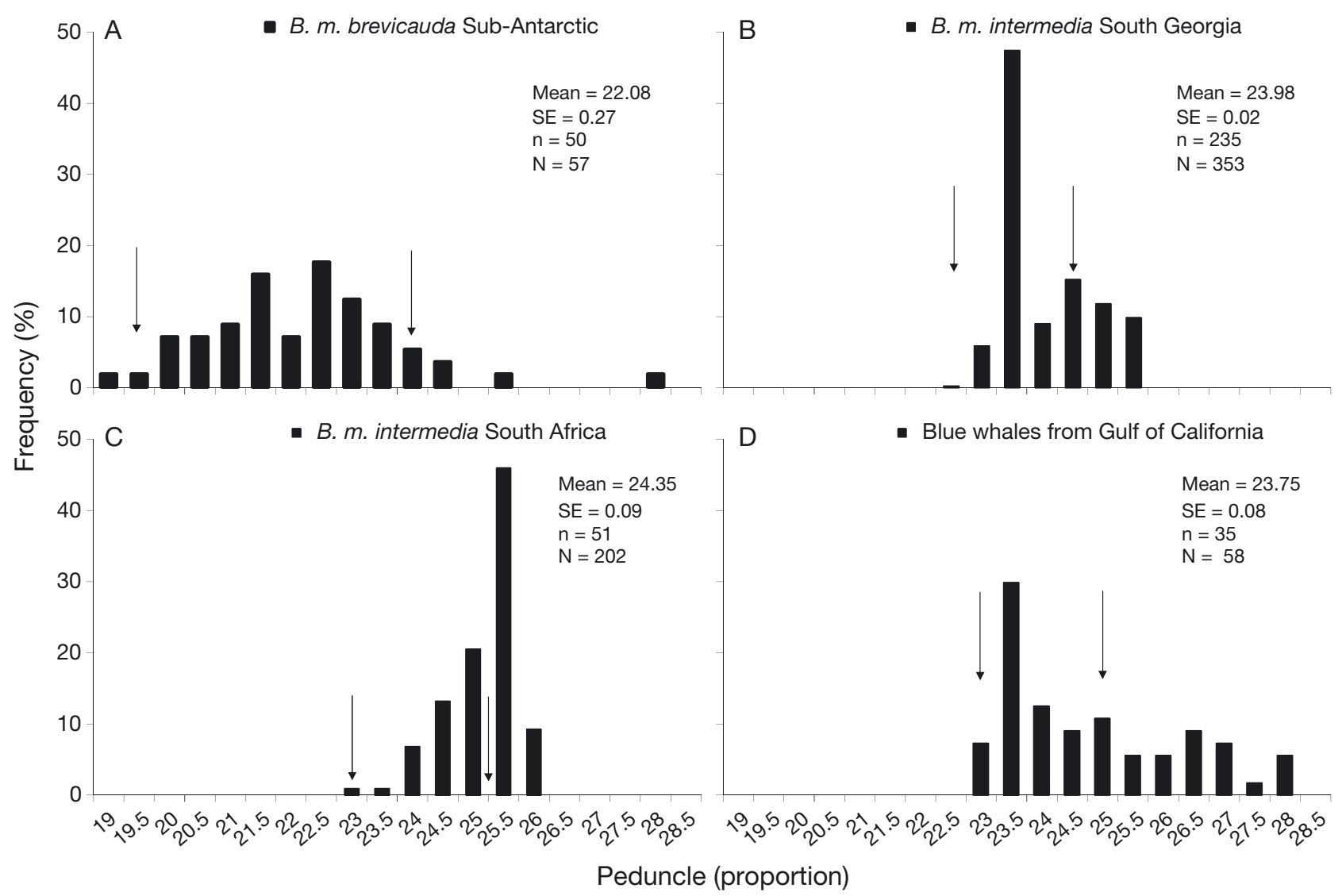

Fig. 4. Frequency distributions of the peduncle proportion (in relation to the total length) for (A) Balaenoptera musculus brevicauda from the Sub-Antarctic (data from Omura 1984); B. m. intermedia from (B) South Georgia and (C) South Africa (data from Mackintosh \& Wheeler 1929); and (D) whales from the Gulf of California (this study). The mean of the peduncle size, its standard error (SE, the uncertainty around the mean value), and sample size (n) for adult individuals are indicated. Black arrows: peduncle proportion range for these adult individuals (length $>20 \mathrm{~m}$ for B. $\mathrm{m}$. brevicauda or $22 \mathrm{~m}$ for B. $\mathrm{m}$. intermedia from whaling data, and peduncle size $<25 \%$ of their total length for Gulf of California individuals). Total sample size including both adults and non-adults $(\mathrm{N})$ is indicated

tion for this inconsistency would be that both $B . \mathrm{m}$. brevicauda and $B$. m. intermedia individuals might have been included in the data set in Omura (1984), which would explain the 2 subspecies overlap found within the Southern Hemisphere (Ljungblad et al. 1998, Branch et al. 2007, Branch \& Mikhalev 2008), and validates the concern expressed by Branch et al. (2007) about the accuracy of the subspecies classification for some individuals labeled as B. m. brevicauda during that whaling operation (Omura 1984). In this regard, Mackintosh \& Wheeler (1929) quoted the possible existence of discrepancies in total length measurements obtained in different whaling areas, but the sources of error were not commented upon. Branch et al. (2007) gave a general overview of the potential problems that affected length measurements in the whaling data, i.e. the use of different metric units, incorrect measurement methods (curvature vs. straight line), incorrect whale position on the deck at the moment of measurement, and stretching or rounding events in order to exceed a minimum allowable catch length. However, measurements from whaling (Mackintosh \& Wheeler 1929, Omura 1984) and VAP used in the present study were standardized with the same protocol and metric unit (the length of a body segment expressed as a percentage of the total length), to avoid bias in our analyses.

Due to this negative allometric growth detected for the caudal peduncle of all blue whale subspecies, we excluded non-adult individuals to enable an unbiased morphometry comparison that allowed detecting differences among subspecies.

\section{Morphometry of blue whale subspecies}

A significant difference was observed between the distribution and means of the caudal peduncle pro- 
portion of all blue whale adult data sets, with the exception of B. m. intermedia from South Georgia and individuals photographed in the Gulf of California (Fig. 4). Differences found in blue whales from South Africa may be related to a predominance of smaller or younger individuals registered in this whaling area (Mackintosh \& Wheeler 1929), which would shift the distribution towards larger caudal peduncle proportions. Nevertheless, caudal peduncle data sets from South Georgia, South Africa and the Gulf of California showed a similar distribution with a very differentiated modal class ranging between 23.5 and $25.5 \%$, in comparison with the distribution of the caudal peduncle proportion of adult B. m. brevicauda that showed the lowest range (19.5 to $24 \%$ ) and an undistinguished modal class (21.5 or $22.5 \%)$. This distribution of the caudal peduncle proportion for B. m. brevicauda would be explained only if these data were from a mixture of $B . \mathrm{m}$. brevicauda and $B$. m. intermedia individuals, supporting the idea of incorrect subspecies classification in the whaling data quoted above.

In summary, the distribution and mean of the caudal peduncle proportion of adult blue whales photographed in the Gulf of California were different from those reported for B. m. brevicauda (Fig. 4).

Since a link between the Gulf of California and California blue whales is known through photorecaptures and satellite tags (Calambokidis et al. 1990, Bailey et al. 2009), we would expect to find similarities with the VAP study on the ENP published by Gilpatrick \& Perryman (2008), who concluded that the ENP blue whale was morphologically similar to Indian Ocean pygmy blue whale $B$. $m$. brevicauda.

Their interpretation was based on total length frequency distributions $(\mathrm{n}=158)$ and the mean of the proportional length of the caudal peduncle $(n=63)$ of free-ranging blue whales measured from California to Central America, which were compared with measurements obtained from whaling operations in the Central and Western North Pacific, as well as the data from the Southern Hemisphere shown in Fig. 4. One difference between the 2 photogrammetry studies is the length at which whales were considered to be adults. The Gilpatrick \& Perryman (2008) analysis included blue whale individuals with total length greater than $19.5 \mathrm{~m}$, which they considered the minimum size for adult and near-adult whales from the ENP, while in our analysis we considered as a cutoff those blue whale individuals with a caudal peduncle proportion $<25 \%$, according to the estimated length at sexual maturity of $20.4 \mathrm{~m}$ reported by Rice (1963).
Additionally, ENP photogrammetry data of Gilpatrick \& Perryman (2008) included whales that were sampled over wide geographical (California to Central America) and temporal (summer-fall 1994 to 2003) scales. Unfortunately, details on sample size by area (California, Baja California and Costa Rica Dome) and months, as well as morphometric data distribution of the caudal peduncle proportion were not included in their publication (only the mean and standard error are given). They combined measurements from whales photographed in the entire geographic area during the same study period (summer-fall), but these whales may not necessarily have come from the same population, or may not be representative of the whole ENP population. Movements of photo-identified and satellite-tagged blue whales between California (summer-fall) and Costa Rica Dome (winter-spring) were previously discovered (Chandler \& Calambokidis 2004, Bailey et al. 2009), but the sampled season (summer-fall) in the Costa Rica Dome by Gilpatrick \& Perryman (2008) does not correspond to this movement pattern. Interestingly, based on their genetic results, LeDuc et al. (2017) suggest that most of the female blue whales sampled during boreal fall (i.e. austral spring) (SeptemberNovember) in the Eastern Tropical Pacific (ETP) were from the Eastern Southern Pacific (ESP) and not from the ENP. Thus, it is possible that the whales photographed in summer-fall by Gilpatrick \& Perryman (2008) were from 2 different populations (Southern Hemisphere at the beginning of their photographic sampling season and Northern Hemisphere during the latter part). Thus, their sample could be made up of whales from both the ESP and the ENP.

In summary, our results indicate that the blue whales photographed in the Gulf of California during the winter-spring period are morphologically different from the pygmy blue whale identified by Omura (1984), otherwise called Indian Ocean pygmy blue whale by Gilpatrick \& Perryman (2008), which has now been genetically linked with the proposed Chilean blue whale subspecies (LeDuc et al. 2017). The integration of both photogrammetric studies (Gilpatrick \& Perryman 2008 and the present study) suggests that 2 morphologically different blue whales use the ENP, which may coincide with the mix of blue whales from both the Northern and Southern Hemispheres found genetically in the ETP by LeDuc et al. (2017).

We believe our results highlight the gaps in our knowledge regarding blue whales inhabiting the ENP and may suggest a need to question the current population stock abundance and status. As Taylor (2005) pointed out, it is necessary to advance the 
pace of cetacean taxonomic descriptions because management and conservation policy assume that the current taxonomy is correct and authoritative.

One thing that makes this a challenging task to study as a whole, is that whale population habitat ranges extend beyond country boundaries. Two examples of outstanding ocean basin research, 'Years of the North Atlantic Humpback' (YoNAH) and 'Structure Population Level Assessment of Humpback' (SPLASH), involved the collaboration of several countries. In that respect, it would be desirable that our peduncle measurements from blue whales photographed in the Gulf of California (one wintering area for the ENP population) be compared with measurements from other parts of the range for this population, such as the feeding area off the California Current System. Finally, in agreement with LeDuc et al. (2017), we believe that if we are to protect the ENP blue whales, it is crucial that a combination of studies, including morphometry, photo-identification, acoustic and molecular analysis as well as endocrinology be undertaken in all known winter breeding and summer feeding grounds in the North and South Pacific oceans and adjacent seas.

Acknowledgements. The authors gratefully acknowledge the contribution of Sandra Lanham, director and pilot of Environmental Flying Services, for her skill in conducting the aerial surveys and funding support, and The Whales \& Dolphin Conservation Society and CONACYT-SEMARNAT 2002-C01-0628 for funding these surveys. We also express our gratitude to Patricio Robles Gil for the use of his aerial images, to the independent measurers (A. Ugalde de la Cruz, F. Guerrero de la Rosa, F. Elorriaga and A. Cedeño) and to W. Perryman, J. Calambokidis and T. Branch for their comments on previous reviewed manuscripts. C.D.O.O. acknowledges CONACYT and PIFI-I.P.N. scholarships.

\section{LITERATURE CITED}

Alling A, Dorsey EM, Gordon CD (1991) Blue whales (Balaenoptera musculus) off the northeast coast of Sri Lanka: distribution, feeding, and individual identification. In: Leatherwood S, Donovan GP (eds) Cetaceans and cetacean research in the Indian Ocean Sanctuary. Marine Mammal Technical Report No. 3. UNEP, Nairobi, p 247-258

Angliss RP, Rugh DJ, Withrow DE, Hobbs RC (1995) Evaluations of aerial photogrammetric length measurements of the Bering-Chukchi-Beaufort seas stock of bowhead whales (Balaena mysticetus). Rep Int Whal Comm 45: 313-324

Armfield BA, George JA, Vinyard CJ, Thewissen JGM (2011) Allometric patterns of fetal head growth in mysticetes and odontocetes: comparison of Balaena mysticetus and Stenella attenuata. Mar Mamm Sci 27:819-827

* Bailey H, Mate BR, Palacios DM, Irvine L, Bograd SJ, Costa DP (2009) Behavioural estimation of blue whale movements in the Northeast Pacific from state-space model analysis of satellite tracks. Endang Species Res 10: 93-106

*Banch TA, Mikhalev YA (2008) Regional differences in length at sexual maturity for female blue whales based on recovered Soviet whaling data. Mar Mamm Sci 24: 690-703

* Branch TA, Abubaker EMN, Mkango S, Butterworth DS (2007) Separating southern blue whale subspecies based on length frequencies of sexually mature females. Mar Mamm Sci 23:803-833

Calambokidis J, Steiger GH, Cubbage JC, Balcomb KC and others (1990) Sighting and movements of blue whales off central California in 1986-88 from photo-identification of individuals. Rep Int Whal Comm Spec Issue 12:343-348

Calambokidis J, Barlow J, Ford JKB, Chandler TE, Douglas $A B$ (2009) Insights into the population structure of blue whales in the Eastern North Pacific from recent sightings and photographic identification. Mar Mamm Sci 25: 816-832

Chandler TE, Calambokidis J (2004) Costa Rica Dome blue whale cruise report. Cascadia Research, Olympia, WA. www.cascadiaresearch.org/publications/costa-rica-domeblue-whale-cruise-report

Cosens SE, Blouw A (2003) Size and age-class segregations of bowhead whales summering in northern Foxe Basin: a photogrammetric analysis. Mar Mamm Sci 19:284-296

* Costa-Urrutia P, Sanvito S, Victoria-Cota N, Enríquez Paredes L, Gendron D (2013) Fine-scale population structure of blue whale wintering aggregations in the Gulf of California. PLOS ONE 8:e58315

Croll D, Marinovic B, Benson S, Chavez F, Black N, Ternullo R, Tershy B (2005) From wind to whales: trophic links in a coastal upwelling system. Mar Ecol Prog Ser 289:117-130

Cubbage JC, Calambokidis J (1987) Size-class segregation of bowhead whales discerned through aerial stereophotogrammetry. Mar Mamm Sci 3:179-185

* Durban JW, Moore MJ, Chiang G, Hickmott LS and others (2016) Photogrammetry of blue whales with an unmanned hexacopter. Mar Mamm Sci 32:1510-1515

* Fiedler PA, Reilly SB, Hewitt RP, Demer D and others (1998) Blue whale habitat and prey in the California Channel Islands. Deep Sea Res II 45:1781-1801

Gambell R (1979) The blue whale. Biologist 26:209-215

Gendron D (2002) Population ecology of the blue whale Balaenoptera musculus from the Baja California peninsula. $\mathrm{PhD}$ dissertation, Centro de Investigación científica y de Educación Superior, Ensenada

Gendron D, Ugalde de la Cruz A (2012) A new classification method to simplify blue whale photo-identification technique. J Cetacean Res Manag 12:79-84

Gilpatrick JW, Perryman WL (2008) Geographic variation in external morphology of North Pacific and Southern Hemisphere blue whales (Balaenoptera musculus). J Cetacean Res Manag 10:9-22

KGoldbogen JA, Potvin J, Shadwick RE (2010) Skull and buccal cavity allometry increase mass-specific engulfment capacity in fin whales. Proc R Soc B 277:861-868

* Huxley JS (1924) Constant differential growth-ratios and their significance. Nature 114:895-896

Huxley JS (1932) Problems of relative growth. Methuen, London

Ichihara T (1961) Blue whales in the waters around Kerguelen island. Nor Hvalfangst-Tid 50:1-20

Ichihara T (1966) The pygmy blue whale, Balaenoptera musculus brevicauda, a new subspecies from the 
Antarctic. In: Norris KS (ed) Whales, dolphins and porpoises. University of California Press, Berkeley, CA, p 79-113

Kato H, Miyashita T, Shimada H (1995) Segregation of the two sub-species of the blue whale in the Southern Hemisphere. Rep Int Whal Comm 45:273-283

Katsanevakis S, Thessalou-Legaki M, Karlou-Riga C, Lefkaditou E, Dimitriou E, Verriopoulos G (2007) Information theory approach to allometric growth of marine organisms. Mar Biol 151:949-959

Larkman VE, Veit RR (1998) Seasonality and abundance of blue whales off southern California. CCOFI Rep 39: 236-239

LeDuc RG, Dizon AE, Goto M, Pastene LA and others (2007) Patterns of genetic variation in the Southern Hemisphere blue whales and the use of assignment test to detect mixing on the feeding grounds. J Cetacean Res Manag 9: $73-80$

LeDuc RG, Archer FI, Lang AR, Martien KK and others (2017) Genetic variation in blue whales in the eastern Pacific: implication for taxonomy and use of common wintering grounds. Mol Ecol 26:740-751

Ljungblad DK, Clark CW, Shimada H (1998) A comparison of sounds attributed to pygmy blue whales (Balaenoptera musculus brevicauda) recorded south of the Madagascar plateau and those attributed to 'true' blue whales (Balaenoptera musculus) recorded off Antarctica. Rep Int Whal Comm 48:439-442

Mackintosh NA, Wheeler JFG (1929) Southern blue and fin whales. Discov Rep 1:257-540

Mate BR, Lagerquist BA, Calambokidis J (1999) Movements of North Pacific blue whales during the feeding season off southern California and their southern fall migration. Mar Mamm Sci 15:1246-1257

McDonald MA, Hildebrand JA, Mesnick SL (2006) Biogeographic characterization of blue whale song worldwide: using song to identify populations. J Cetacean Res Manag 8:55-65

Monnahan CC, Branch TA, Punt AE (2015) Do ship strikes threaten the recovery of endangered eastern North Pacific blue whales? Mar Mamm Sci 31:279-297

Omura H (1984) Measurements of body proportions of the pygmy blue whale, left by the late Dr. Tadayoshi Ichihara. Sci Rep Whales Res Inst 35:199-203

Paniagua-Mendoza A, Gendron D, Romero-Vivas E, Hildebrand JA (2017) Seasonal acoustic behavior of blue whales (Balaenoptera musculus) in the Gulf of California, Mexico. Mar Mamm Sci 33:206-218

Perryman WL, Lynn MS (1993) Identification of geographic forms of common dolphin (Delphinus delphis) from aerial photogrammetry. Mar Mamm Sci 9:119-137
Ratnaswamy MJ, Winn HE (1993) Photogrammetric estimates of allometry and calf production in fin whales, Balaenoptera physalus. J Mammal 74:323-330

Reilly SB, Bannister JL, Best PB, Brown M and others (2008) Balaenoptera musculus. The IUCN Red List of Threatened Species 2008: e.T2477A9447146. www.iucnredlist. org/details/2477/0 (accessed 5 Sep 2018)

Rice DW (1963) Progress report on biological studies of the larger cetaceans in the waters off California. Nor Hvalfangst-Tid 7:181-187

Rice DW (1974) Whales and whale research in the Eastern North Pacific. In: Shevill WF (ed) The whale problem: a status report. Harvard University Press, Cambridge, MA, p 170-195

Rice DW (1998) Marine mammals of the world: systematics and distribution. Special Publication No. 4, The Society for Marine Mammalogy. Allen Press, Lawrence, KS

Schmidt-Nielsen K (1984) Scaling. Why is animal size so important? Cambridge University Press, Cambridge

* Schoenherr JR (1991) Blue whales feeding on high concentrations of euphausiids around Monterey Submarine Canyon. Can J Zool 69:583-594

Sears R, Calambokidis J (2002) Update COSEWIC status report on the blue whales Balaenoptera musculus in Canada. Committee on the Status of Endangered Wildlife in Canada, Ottawa

* Sears R, Ramp C, Douglas AB, Calambokidis J (2013) Reproductive parameters of eastern North Pacific blue whales Balaenoptera musculus. Endang Species Res 22:23-31

Stafford KM, Nieukirk SL, Fox CG (2001) Geographical and seasonal variation of blue whale calls in the North Pacific. J Cetacean Res Manag 3:65-76

Steel RGD, Torrie JH (1988) Biostatistics: principles and procedures. McGraw Hill, New York, NY

Taylor BL (2005) Identifying units to conserve. In: Reynolds JE III, Perrin WF, Reeves RR, Montgomery S, Ragen TJ (eds) Marine mammal research, conservation beyond crisis. The Johns Hopkins University Press, Baltimore, MD, p 149-162

* Valdez-Márquez M, Lares ML, Camacho-Ibar V, Gendron D (2004) Chlorinated hydrocarbons in skin and blubber of two blue whales (Balaenoptera musculus) stranded along the Baja California coast. Bull Environ Contam Toxicol 72:490-495

*Valenzuela-Molina M, Atkinson S, Mashburn K, Gendron D, Brownell RL Jr (2018) Fecal steroid hormones reveal reproductive state in female blue whales sampled in the Gulf of California, Mexico. Gen Comp Endocrinol 261: $127-135$

Zar JH (1996) Biostatistical analysis, 3rd edn. Prentice Hall, Upper Saddle River, NJ 
Appendix. Sources of variability in the photogrammetric data

The technical error $\left(E_{1}\right)$, the error of the measurement of the locker, expressed as a percentage of the total length of the boat, was calculated as the average of absolute residuals, i.e. the mean of the absolute value of differences between each measure and the true value for the locker:

$$
E_{1}=\frac{1}{n} \sum_{i=1}^{n}\left|X_{i}-X\right|
$$

where: $x_{i}=i^{\text {th }}$ measurement of the locker, $X=$ true value of the locker and $n=$ number of aerial images of the boat that were measured.

Biological variability $\left(E_{2}\right)$. In each image, the peduncle proportion was measured and estimated as the average of residuals regarding the mean value of each individual:

$$
E_{2}=\frac{1}{N} \sum_{i=1}^{N}\left[\frac{1}{n_{i}} \sum_{j=1}^{n_{i}}\left|x_{i j}-\bar{X}_{i}\right|\right]
$$

where $x_{i j}=j^{\text {th }}$ measurement of whale $i, \bar{X}_{\mathrm{i}}$ average of estimations of whale $i, n_{i}=$ number of images of whale $i$, and $N=$ number of whales.

Observer variability $\left(E_{3}\right)$ was calculated as the mean error of absolute differences regarding the mean value of estimates made by the 3 observers of each image:

$$
E_{3}=\frac{1}{N} \sum_{i=1}^{N}\left[\frac{1}{3} \sum_{j=1}^{3}\left|x_{i j}-\bar{X}_{i}\right|\right]
$$

where $x_{i j}=$ measurement of image $i$ made by observer $j, \bar{X}_{i}$ average of estimations of image $i$ and $N=$ number of images.

Editorial responsibility: Jaume Forcada, Cambridge, UK
Submitted: November 24, 2017; Accepted: June 14, 2018 Proofs received from author(s): September 8, 2018 